\title{
Pemetrexed Plus Platinum for Patients With Advanced Non-small Cell Lung Cancer and Interstitial Lung Disease
}

\author{
TETSUO FUJITA ${ }^{1}$, TSUGUKO KUROKI ${ }^{1}$, NAMI HAYAMA ${ }^{1}$, YUKA SHIRAISHI ${ }^{1}$, HIROYUKI AMANO ${ }^{1}$, \\ MAKOTO NAKAMURA ${ }^{1}$, SATOSHI HIRANO ${ }^{2}$, HIROSHI TABETA ${ }^{1}$ and SUKEYUKI NAKAMURA ${ }^{1}$ \\ ${ }^{1}$ Department of Respirology, Funabashi Municipal Medical Center, Kanasugi, Japan; \\ ${ }^{2}$ Department of Medical Oncology, Funabashi Municipal Medical Center, Kanasugi, Japan
}

\begin{abstract}
Background/Aim: Pemetrexed plus platinum followed by pemetrexed maintenance has been one of the standard first-line treatments in advanced nonsquamous nonsmall cell lung cancer (NSCLC), but little is known regarding its safety and efficacy for patients with interstitial lung disease (ILD). Patients and Methods: The medical records of 24 patients with advanced nonsquamous NSCLC and preexisting ILD who received pemetrexed and platinum doublet therapy with and without pemetrexed maintenance in the first-line setting between December 2009 and June 2016, were retrospectively reviewed. Results: The median progression-free survival time was 4.7 months, and the median overall survival time was 9.5 months. Of the 24 patients analyzed, six received pemetrexed maintenance. Acute exacerbation of ILD (AE-ILD) occurred in five $(20.8 \%)$ of 24 patients, including two fatal cases. Conclusion: The treatment with pemetrexed plus platinum has a high risk of AE-ILD in patients with advanced nonsquamous NSCLC and preexisting ILD.
\end{abstract}

Recently, treatment of patients with advanced lung cancer, especially nonsquamous non-small cell lung cancer (NSCLC) has been improving and diversifying. Molecular target-based therapies such as epidermal growth factor receptor tyrosine kinase inhibitors (EGFR-TKIs) and anaplastic lymphoma tyrosine kinase inhibitors (ALK-TKIs) have significant efficacy in patients with nonsquamous NSCLC having the corresponding driver mutations $(1,2)$. Immune checkpoint inhibitors (ICIs) have also benefited patients with advanced

This article is freely accessible online.

Correspondence to: Tetsuo Fujita, Department of Respirology, Funabashi Municipal Medical Center, 1-21-1 Kanasugi, Chiba 2738588, Japan. Tel: +81 474383321, Fax: +81 474387323, e-mail: phajita0318@yahoo.co.jp

Key Words: Nonsquamous non-small-cell lung cancer, interstitial lung disease, pemetrexed, platinum.
NSCLC, especially those with high PD-L1 expression on tumor cells (3). However, a higher incidence of drug-related ILD was reported in patients treated with TKIs and ICIs compared to those treated with cytotoxic agents (3-5). Preexisting ILD is a risk factor for drug-related ILD and its risk is considered to be higher when using EGFR-TKIs or ICIs compared with cytotoxic chemotherapy. Therefore, in clinical practice, most physicians avoid these targeted therapies and immune checkpoint therapies for NSCLC patients with preexisting ILD and instead select cytotoxic platinum-based chemotherapy. However, optimal chemotherapy using other agents has not yet been established.

Pemetrexed has been a key drug in the treatment of nonsquamous NSCLC. Pemetrexed and cisplatin combination chemotherapy has been one of the most evaluated regimens in the first-line setting for patients with advanced nonsquamous NSCLC (6). Pemetrexed is even used in the maintenance setting because of its efficacy and low cumulative toxicity. The PARAMOUNT study revealed that in patients with advanced nonsquamous NSCLC, continuation of maintenance therapy with pemetrexed following induction therapy with pemetrexed and cisplatin significantly improved progressionfree survival (PFS) and overall survival (OS) (7). Similarly, pemetrexed plus carboplatin followed by pemetrexed maintenance has been recognized as a standard regimen for nonsquamous NSCLC and is widely used in clinical practice (8). However, little is known about the safety and efficacy of combination chemotherapy of pemetrexed plus platinum with and without pemetrexed maintenance for patients with nonsquamous NSCLC and preexisting ILD. Thus, we conducted a retrospective study to determine whether combination chemotherapy of pemetrexed plus platinum with or without pemetrexed maintenance is a feasible treatment option in nonsquamous NSCLC patients with ILD.

\section{Patients and Methods}

Patients and treatment methods. The medical records of 24 patients of advanced nonsquamous NSCLC with preexisting ILD who received 
Table I. Patient characteristics $(n=24)$.

\begin{tabular}{|c|c|c|c|c|}
\hline Characteristics & $\begin{array}{l}\text { All patients } \\
\quad(\mathrm{n}=24)\end{array}$ & $\begin{array}{l}\text { Maintenance group } \\
\qquad(\mathrm{n}=6)\end{array}$ & $\begin{array}{l}\text { No maintenance group } \\
\qquad(\mathrm{n}=12)\end{array}$ & $p$-Value \\
\hline Gender (male/female) & $22 / 2$ & $6 / 0$ & $11 / 1$ & 0.667 \\
\hline Median age (years) (range) & $70(56-80)$ & $71.5(64-80)$ & $68.5(56-79)$ & 0.851 \\
\hline Smoking status (never/former or current) & $1 / 23$ & $0 / 6$ & $1 / 11$ & 0.667 \\
\hline Performance status $(0-1 / 2)$ & $22 / 2$ & $6 / 0$ & $11 / 1$ & 0.667 \\
\hline Stage (IIIa or IIIb/IV or recurrence) & $8 / 16$ & $1 / 5$ & $4 / 8$ & 0.439 \\
\hline Combined with emphysema (yes/no) & $16 / 8$ & $4 / 2$ & $7 / 5$ & 0.572 \\
\hline ILD radiological pattern (UIP/non-UIP) & $2 / 22$ & $1 / 5$ & $1 / 11$ & 0.569 \\
\hline Median \%VC (predicted) (\%) (range) & $91.2(61.0-122.2)$ & $90.7(81.7-122.2)$ & $90.0(61.0-101.2)$ & 0.581 \\
\hline Median $\%$ FEV1 (predicted) (\%) (range) & $93.5(60.8-130.7)$ & $91.2(66.8-130.7)$ & $98.1(60.8-109.4)$ & 0.713 \\
\hline Median FEV1\% (range) & $75.3(49.9-87.3)$ & $72.8(49.9-79.5)$ & $75.9(66.1-86.4)$ & 0.142 \\
\hline Platinum regimen (cisplatin/carboplatin) & $10 / 14$ & $3 / 3$ & $6 / 6$ & 0.690 \\
\hline
\end{tabular}

IIPs: Idiopathic interstitial pneumonias; UIP: usual interstitial pneumonia; \%VC: \%vital capacity; \%FEV1: \% forced expiratory volume in one second; FEV1\%: ratio of forced expiratory volume in one second to forced vital capacity.

Table II. Response to pemetrexed and platinum doublet therapy.

\begin{tabular}{lc}
\hline Response & $\mathrm{n}$ \\
\hline Complete response & 0 \\
Partial response & 8 \\
Stable disease & 12 \\
Progressive disease & 4 \\
\hline & $\%$ \\
\hline Overall response rate & 33.3 \\
Disease control rate & 80.0 \\
\hline
\end{tabular}

pemetrexed plus platinum doublet chemotherapy as the first-line treatment at Funabashi Municipal Medical Center between December 2009 and June 2016 were retrospectively reviewed. ILD was identified by clinical features and computed tomography (CT) images obtained prior to chemotherapy. The presence of ILD was evaluated by at least two pulmonologists and the preexisting ILD patterns were divided into usual interstitial pneumonia (UIP) pattern and non-UIP pattern in accordance with the International Consensus Statement (9).

Pemetrexed and platinum (cisplatin or carboplatin) were administered on day 1 every three weeks. After four or six cycles, some of the patients without disease progression underwent maintenance therapy with pemetrexed every three weeks. Pemetrexed and cisplatin were administered at a dose of $500 \mathrm{mg} / \mathrm{m}^{2}$ and $75 \mathrm{mg} / \mathrm{m} 2$, respectively. Carboplatin was administered at a dose determined by the area under the curve 5 .

Clinical evaluation and adverse events. The overall response rate (ORR) and the disease control rate (DCR) were assessed based on the Response Evaluation Criteria in Solid Tumor (RECIST) guidelines (10). Adverse events were graded according to the Common Terminology Criteria for Adverse Events, version 4.0. AE-
ILD was defined on the basis of CT with new bilateral ground-glass opacities and/or consolidation superimposed on a background reticular pattern or honeycombing. Cases with other diseases such as congestive heart failure, apparent pulmonary infection and pulmonary embolism were excluded (11). In addition, the imaging findings of AE-ILD were classified into diffuse alveolar damage (DAD) type or non-DAD type based on the consensus statement of Japanese Respiratory Society (12).

Statistical methods. PFS was defined as the duration between the start of treatment and the date of disease progression or death from any cause. OS was measured from the start of treatment until death or the last follow-up examination. Event time was estimated using the Kaplan-Meier method.

\section{Results}

Patient characteristics. The baseline characteristics of the 24 patients are summarized in Table I. Two patients were women and the median age was 70 years (range $=56-80$ years). One patient who had rheumatoid arthritis was never a smoker and was diagnosed with interstitial pneumonitis associated with rheumatoid arthritis. All patients except the one were current or past smokers, and ILD of these patients was diagnosed as idiopathic interstitial pneumonitis. Two patients had an Eastern Cooperative Oncology Group performance status (PS) of two and the others had PS of 0 or 1 . Eight patients had stage III disease and the others had stage IV or recurrent disease. The median $\%$ vital capacity (\%VC: VC/predicted VC) was 91.2\% (range=61.0-122.2\%), and the median $\%$ forced expiratory volume in one second (\%FEV1: FEV1/predicted FEV1) was 93.5\% (range=60.8$105.6 \%)$. A total of 16 patients also had pulmonary emphysema and four were diagnosed as having COPD (FEV1/Forced VC ratio $<0.7$ ). Ten patients received cisplatin 
a

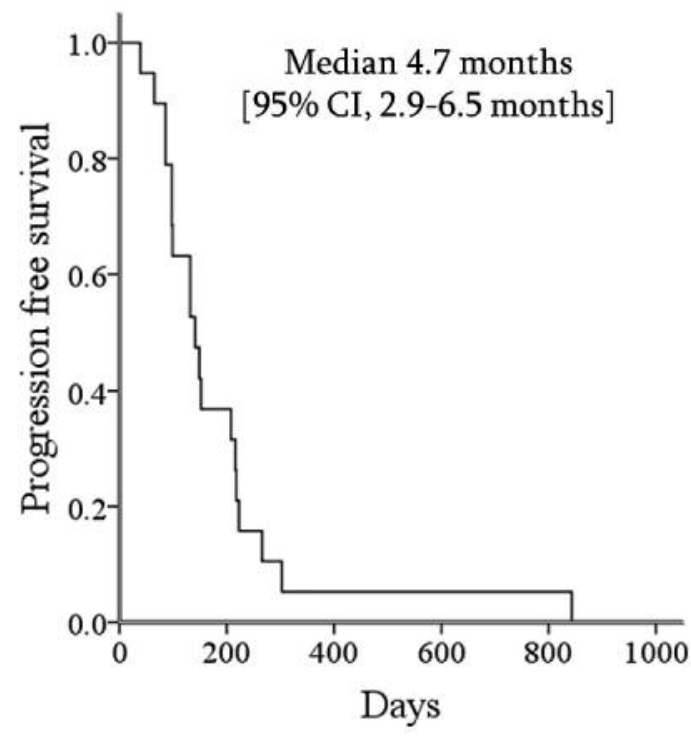

b

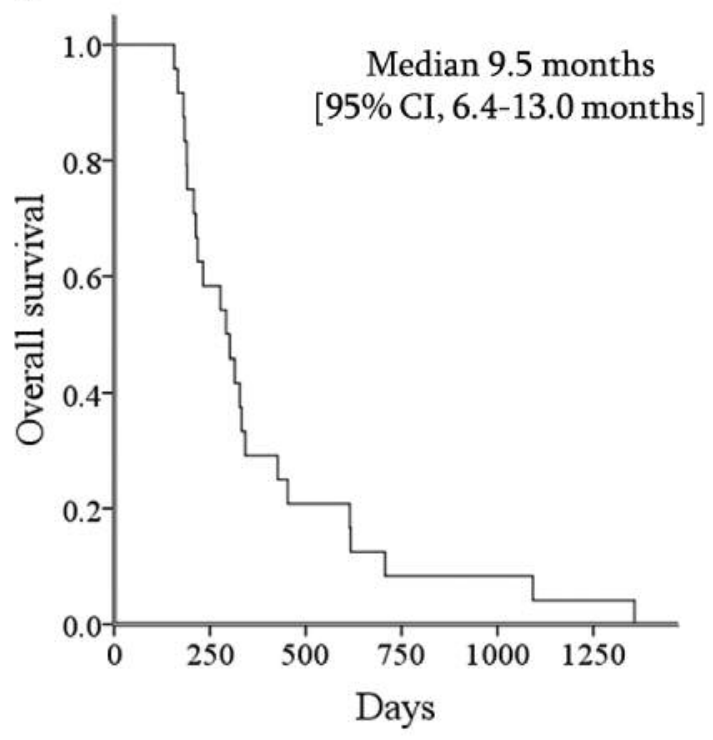

Figure 1. Kaplan-Meier curves for progression-free survival (a) and overall survival (b).

and the others received carboplatin as platinum agents. Based on pretreatment CT scan of the chest, UIP and nonUIP patterns were observed in two $(8.3 \%)$ and $22(91.7 \%)$ patients, respectively. Among patients who were not progressed after four cycles of pemetrexed and platinum doublet therapy, there were no significant differences between the maintenance group $(n=6)$ and the nonmaintenance group $(n=12)$.

Treatment exposure and efficacy. The median number of treatment cycles for pemetrexed and platinum doublet therapy was 4 (range=2-6 cycles). In the 24 patients analyzed, ORR was $33.3 \%$ and DCR was $80 \%$ in pemetrexed and platinum doublet therapy (Table II). The median PFS and the median OS of all patients were 4.7 months and 9.5 months, respectively (Figure 1a, b). The one-year survival rate was $24.2 \%$. Of 18 patients who did not progress after four cycles of pemetrexed and platinum doublet therapy, 6 received pemetrexed maintenance therapy. In 18 patients receiving only the doublet therapy, the median PFS and the median OS were 4.4 months and 9.5 months, respectively. The median number of pemetrexed maintenance cycles was 2 (range $=2-4$ cycles). The median OS of the maintenance group was 9.2 months $(95 \% \mathrm{CI}=0-26.5$ months $)$ compared with 10.0 months $(95 \% \mathrm{CI}=8.8-11.4$ months) for the nonmaintenance group $(p=0.197)$.

Toxicity. The adverse events from pemetrexed and platinum doublet therapy are summarized in Table III. The most frequently reported hematological adverse events of grade $\geq$ 3 were anemia $(6 / 24,25 \%)$ and thrombocytopenia $(25 \%)$. Two patients developed grade 4 neutropenia but no patients experienced febrile neutropenia. Regarding nonhematological adverse events, the most frequently adverse event was anorexia in seven patients $(29 \%)$. There were no adverse events of grade $\geq 3$ except AE-ILD and respiratory failure during pemetrexed maintenance therapy.

$A E-I L D$ and treatment-related death. Chemotherapy-related AE-ILD was observed in three patients during pemetrexed and platinum doublet therapy and in two patients during pemetrexed maintenance therapy. Treatment-related deaths occurred in one patient (AE-ILD) during the doublet therapy and in two patients (AE-ILD: 1, respiratory failure: 1) during the maintenance therapy. The CT findings showed DAD pattern only in one fatal AE-ILD case during the doublet therapy and non-DAD pattern in the other AE-ILD cases. During the sequential therapies, AE-ILD developed in five patients who received docetaxel or S-1, including two fatal cases.

\section{Discussion}

Pemetrexed, an anti-folate that is structurally similar to methotrexate, is known to cause ILD in patients with rheumatoid arthritis (13). Recently, Tomii et al. have reported that the incidence of pemetrexed-related ILD was $1.8 \%$ (12/683 patients) in NSCLC Japanese patients (14). 
in vivo 33: $2059-2064(2019)$

Table III. Treatment-related adverse events during pemetrexed and platinum doublet therapy.

\begin{tabular}{|c|c|c|c|c|c|c|}
\hline \multirow[t]{2}{*}{ Toxicity } & \multicolumn{6}{|c|}{ Grade } \\
\hline & 1 & 2 & 3 & 4 & 5 & $3-5(\%)$ \\
\hline Leukopenia & 8 & 3 & 2 & 0 & 0 & 8.3 \\
\hline Neutropenia & 5 & 2 & 3 & 2 & 0 & 20.8 \\
\hline Thrombocytopenia & 8 & 1 & 4 & 2 & 0 & 25.0 \\
\hline Anemia & 9 & 10 & 5 & 1 & 0 & 25.0 \\
\hline Febrile neutropenia & - & - & 0 & 0 & 0 & 0 \\
\hline Creatinine increased & 1 & 3 & 0 & 0 & 0 & 0 \\
\hline Anorexia & 1 & 6 & 0 & 0 & 0 & 0 \\
\hline Nausea & 0 & 2 & 0 & 0 & 0 & 0 \\
\hline Vomiting & 1 & 0 & 0 & 0 & 0 & 0 \\
\hline Constipation & 4 & 0 & 0 & 0 & 0 & 0 \\
\hline Oral mucositis & 0 & 2 & 0 & 0 & 0 & 0 \\
\hline Diarrhea & 0 & 2 & 0 & 0 & 0 & 0 \\
\hline Hiccups & 2 & 0 & 0 & 0 & 0 & 0 \\
\hline Pulmonary fibrosis & 0 & 0 & 0 & 2 & 1 & 12.5 \\
\hline
\end{tabular}

They insisted that the risk of pemetrexed-related ILD may be at a level similar to other cytotoxic agents and pemetrexed-induced ILD responded well to steroid treatment. On the other hand, Kato et al. have reported that pemetrexed-induced AE-ILD occurred in three (12\%) of 25 patients with NSCLC and preexisting ILD who were treated with pemetrexed monotherapy, and all three patients died from the drug-related ILD (15). Therefore, there is need to carefully assess whether pemetrexed containing regimens can become feasible treatment options as first-line chemotherapy for nonsquamous NSCLC patients with preexisting ILD.

Paclitaxel containing regimens are the most common and well evaluated first line regimens for advanced NSCLC with preexisting ILD (16-19). Minegishi et al. have conducted a prospective study of paclitaxel plus carboplatin doublet chemotherapy for advanced NSCLC and preexisting ILD, and showed that the median PFS and the median OS were 5.3 months and 10.6 months, respectively (16). The present study showed the median PFS and the median OS were 4.7 months and 9.5 months, respectively, suggesting that the efficacy of pemetrexed plus platinum doublet chemotherapy followed by maintenance of pemetrexed may not be superior to paclitaxel plus carboplatin doublet chemotherapy.

The incidence of AE-ILD in paclitaxel plus carboplatin doublet chemotherapy has been reported to be $5.6 \%$ ( 1 in 18 patients) in a prospective study (16) and 7.9\% (5 in 63 patients) in a largest retrospective study by Kenmotsu et al. (17). On the other hand, limited information is available regarding the role of the first-line regimen containing pemetrexed for lung cancer patients with preexisting ILD. Choi et al. have retrospectively analyzed 52 patients with advanced NSCLC and preexisting ILD treated with gemcitabine or pemetrexed plus platinum (20). They have reported that the incidence of AE-ILD was 5.8\% (3 in 52 patients) and concluded that pemetrexed plus platinum could be a feasible regimen for NSCLC and preexisting ILD. However, two among the three AE-ILD cases in their study received pemetrexed plus cisplatin doublet chemotherapy and they both died from AE-ILD, meaning that the incidence of AE-ILD in patients treated with pemetrexed plus platinum was $15.4 \%$ ( 2 in 13 patients). In the present study, AE-ILD occurred in five $(20.8 \%)$ of 24 patients with ILD who received platinum plus pemetrexed with and without pemetrexed maintenance, with three cases and two cases experiencing AE-ILD during the doublet phase and maintenance phase, respectively. Among the five patients, two died due to the AE-ILD. These findings suggest that the incidence of drug-related AE-ILD in chemotherapy containing pemetrexed may be higher than that in paclitaxel plus carboplatin doublet chemotherapy, and pemetrexed containing regimens can cause fatal ILD with high frequency in patients with preexisting ILD.

This study has several limitations. First, the number of patients was small. Second, it was a retrospective analysis performed at a single institution, and larger scale studies are needed. Third, the diagnosis of ILD and AE-ILD was based on CT findings and not on histological examinations.

Considering the high frequency of AE-ILD in chemotherapy containing pemetrexed for patients with preexisting ILD, pemetrexed-containing regimens should not be administered for such patients.

\section{Conflicts of Interest}

The Authors declare that they have no conflicts of interest regarding this study. 


\section{Authors' Contributions}

T.F. designed the work and wrote the paper. M.N and H.A. contributed to evaluation of radiological findings. All other Authors have contributed to data collection and interpretation, and critically reviewed the manuscript. All Authors approved the final version of the manuscript, and agree to be accountable for all aspects of the work in ensuring that questions related to the accuracy or integrity of any part of the work are appropriately investigated and resolved.

\section{Acknowledgements}

The Authors thank Chihiro George Kurokawa of the United States for editing the manuscript.

\section{References}

1 Maemondo M, Inoue A, Kobayashi K, Sugawara S, Oizumi S, Isobe H, Gemma A, Harada M, Yoshizawa H, Kinoshita I, Fujita Y, Okinaga S, Hirano H, Yoshimori K, Harada T, Ogura T, Ando M, Miyazawa H, Tanaka T, Saijo Y, Hagiwara K, Morita S, Nukiwa $\mathrm{T}$ and North-East Japan Study Group: Gefitinib or chemotherapy for non-small-cell lung cancer with mutated EGFR. N Engl J Med 362: 2380-2388, 2010. PMID: 20573926. DOI: $10.1056 /$ NEJMoa0909530

2 Solomon BJ, Mok T, Kim DW, Wu YL, Nakagawa K, Mekhail T, Felip E, Cappuzzo F, Paolini J, Usari T, Iyer S, Reisman A, Wilner KD, Tursi J, Blackhall $\mathrm{F}$ and PROFILE 1014 Investigators: First-line crizotinib versus chemotherapy in ALKpositive lung cancer. N Engl J Med 371: 2167-2177, 2014 PMID: 25470694. DOI: 10.1056/NEJMoa1408440

3 Reck M, Rodriguez-Abreu D, Robinson AG, Hui R, Csőszi T, Fülöp A, Gottfried M, Peled N, Tafreshi A, Cuffe S, O'Brien M1, Rao S, Hotta K, Leiby MA, Lubiniecki GM, Shentu Y, Rangwala R, Brahmer JR and KEYNOTE-024 Investigators. Pembrolizumab versus chemotherapy for PD-L1-positive nonsmall-cell lung cancer. N Engl J Med 375: 1823-1833, 2016. PMID: 27718847. DOI: 10.1056/NEJMoa1606774

4 Kudoh S, Kato H, Nishiwaki Y, Fukuoka M, Nakata K, Ichinose Y, Tsuboi M, Yokota S, Nakagawa K, Suga M, Jiang H, Itoh Y, Armour A, Watkins C, Higenbottam T and Nyberg F: Interstitial lung disease in Japanese patients with lung cancer: a cohort and nested case-control study. Am J Respir Crit Care Med 177: 1348-1357, 2008. PMID: 18337594. DOI: 10.1164/rccm.2007 10-15010C

5 Brahmer J, Reckamp KL, Baas P, Crino L, Eberhardt WE, Poddubskaya E, Antonia S, Pluzanski A, Vokes EE, Holgado E, Waterhouse D, Ready N, Gainor J, Aren Frontera O, Havel L, Steins M, Garassino MC, Aerts JG, Domine M, Paz-Ares L, Reck M, Baudelet C, Harbison CT, Lestini B and Spigel DR: Nivolumab versus docetaxel in advanced squamous-cell nonsmall-cell lung cancer. N Engl J Med 373: 123-135, 2015. PMID: 26028407. DOI: 10.1056/NEJMoa1504627

6 Scagliotti GV, Parikh P, von Pawel J, Biesma B, Vansteenkiste J, Manegold C, Serwatowski P, Gatzemeier U, Digumarti R, Zukin M, Lee JS, Mellemgaard A, Park K, Patil S, Rolski J, Goksel T, de Marinis F, Simms L, Sugarman KP and Gandara D: Phase III study comparing cisplatin plus gemcitabine with cisplatin plus pemetrexed in chemotherapy-naive patients with advanced-stage non-small-cell lung cancer. J Clin Oncol 26: 3543-3551, 2008. PMID: 18506025. DOI: 10.1200/JCO.2007. 15.0375

7 Paz-Ares LG, de Marinis F, Dediu M, Thomas M, Pujol JL, Bidoli P, Molinier O, Sahoo TP, Laack E, Reck M, Corral J, Melemed S, John W, Chouaki N, Zimmermann AH, VisserenGrul C and Gridelli C: PARAMOUNT: Final overall survival results of the phase III study of maintenance pemetrexed versus placebo immediately after induction treatment with pemetrexed plus cisplatin for advanced nonsquamous non-small-cell lung cancer. J Clin Oncol 31: 2895-2902, 2013. PMID: 23835707. DOI: $10.1200 / J C O .2012 .47 .1102$

8 Zinner RG, Obasaju CK, Spigel DR, Weaver RW, Beck JT, Waterhouse DM, Modiano MR, Hrinczenko B, Nikolinakos PG, Liu J, Koustenis AG, Winfree KB, Melemed SA, Guba SC, Ortuzar WI, Desaiah D, Treat JA, Govindan R and Ross HJ: PRONOUNCE: randomized, open-label, phase III study of firstline pemetrexed + carboplatin followed by maintenance pemetrexed versus paclitaxel + carboplatin + bevacizumab followed by maintenance bevacizumab in patients ith advanced nonsquamous non-small-cell lung cancer. J Thorac Oncol 10: 134-142, 2015. PMID: 25371077. DOI: 10.1097/JTO.0000 000000000366

9 Raghu G, Collard HR, Egan JJ, Martinez FJ, Behr J, Brown KK, Colby TV, Cordier JF, Flaherty KR, Lasky JA, Lynch DA, Ryu JH, Swigris JJ, Wells AU, Ancochea J, Bouros D, Carvalho C, Costabel U, Ebina M, Hansell DM, Johkoh T, Kim DS, King TE, Jr., Kondoh Y, Myers J, Muller NL, Nicholson AG, Richeldi L, Selman M, Dudden RF, Griss BS, Protzko SL and Schunemann HJ: An official ATS/ERS/JRS/ALAT statement: idiopathic pulmonary fibrosis: evidence-based guidelines for diagnosis and management. Am J Respir Crit Care Med 183: 788-824, 2011. PMID: 21471066. DOI: $10.1164 / \mathrm{rccm} .2009-040 \mathrm{GL}$

10 Eisenhauer EA, Therasse P, Bogaerts J, Schwartz LH, Sargent D, Ford R, Dancey J, Arbuck S, Gwyther S, Mooney M, Rubinstein L, Shankar L, Dodd L, Kaplan R, Lacombe D and Verweij J: New response evaluation criteria in solid tumours: revised RECIST guideline (version 1.1). Eur J Cancer 45: 228247, 2009. PMID: 19097774. DOI: 10.1016/j.ejca.2008.10.026

11 Collard HR, Moore BB, Flaherty KR, Brown KK, Kaner RJ, King TE Jr., Lasky JA, Loyd JE, Noth I, Olman MA, Raghu G, Roman J, Ryu JH, Zisman DA, Hunninghake GW, Colby TV, Egan JJ, Hansell DM, Johkoh T, Kaminski N, Kim DS, Kondoh Y, Lynch DA, Muller-Quernheim J, Myers JL, Nicholson AG, Selman M, Toews GB, Wells AU and Martinez FJ: Acute exacerbations of idiopathic pulmonary fibrosis. Am J Respir Crit Care Med 176: 636-643, 2007. PMID: 17585107. DOI: 10.1164/ rccm.200703-463PP

12 Kubo K, Azuma A, Kanazawa M, Kameda H, Kusumoto M, Genma A, Saijo Y, Sakai F, Sugiyama Y, Tatsumi K, Dohi M, Tokuda H, Hashimoto S, Hattori N, Hanaoka M and Fukuda Y: Consensus statement for the diagnosis and treatment of druginduced lung injuries. Respir Investig 51: 260-277, 2013. PMID: 24238235. DOI: 10.1016/j.resinv.2013.09.001

13 Imokawa S, Colby TV, Leslie $\mathrm{KO}$ and Helmers RA: Methotrexate pneumonitis: review of the literature and histopathological findings in nine patients. Eur Respir J 15: 373381, 2000. PMID: 10706507.

14 Tomii K, Kato T, Takahashi M, Noma S, Kobashi Y, Enatsu S, Okubo S, Kobayashi $\mathrm{N}$ and Kudoh S: Pemetrexed-related 
interstitial lung disease reported from post marketing surveillance (malignant pleural mesothelioma/non-small cell lung cancer). Jpn J Clin Oncol 47: 350-356, 2017. PMID: 28158568. DOI: $10.1093 /$ jjco/hyx010

15 Kato M, Shukuya T, Takahashi F, Mori K, Suina K, Asao T, Kanemaru R, Honma Y, Muraki K, Sugano K, Shibayama R, Koyama R, Shimada N and Takahashi K: Pemetrexed for advanced non-small cell lung cancer patients with interstitial lung disease. BMC Cancer 14: 508, 2014. PMID: 25012241. DOI: $10.1186 / 1471-2407-14-508$

16 Minegishi Y, Sudoh J, Kuribayasi H, Mizutani H, Seike M, Azuma A, Yoshimura A, Kudoh S and Gemma A: The safety and efficacy of weekly paclitaxel in combination with carboplatin for advanced non-small cell lung cancer with idiopathic interstitial pneumonias. Lung Cancer 71: 70-74, 2011. PMID: 20493578. DOI: 10.1016/j.lungcan.2010.04.014

17 Kenmotsu H, Naito T, Mori K, Ko R, Ono A, Wakuda K, Imai H, Taira T, Murakami H, Endo $M$ and Takahashi T: Effect of platinum-based chemotherapy for non-small cell lung cancer patients with interstitial lung disease. Cancer Chemother Pharmacol 75: 521-526, 2015. PMID: 25563718. DOI: 10.1007/ s00280-014-2670-y

18 Shimizu R, Fujimoto D, Kato R, Otoshi T, Kawamura T, Tamai K, Matsumoto T, Nagata K, Otsuka K, Nakagawa A, Katakami N and Tomii K: The safety and efficacy of paclitaxel and carboplatin with or without bevacizumab for treating patients with advanced nonsquamous non-small cell lung cancer with interstitial lung disease. Cancer Chemother Pharmacol 74: 1159-1166, 2014. PMID: 25245821. DOI: 10.1007/s00280-014-2590-x014
19 Fujita T, Hiroishi T, Shikano K, Yanagisawa A, Hayama N, Amano H, Nakamura M, Hirano S, Tabeta $\mathrm{H}$ and Nakamura S: The safety and efficacy of treatment with nab-paclitaxel and carboplatin for patients with advanced squamous non-small cell lung cancer concurrent with idiopathic interstitial pneumonias. Intern Med 57: 1827-1832, 2018. PMID: 29434143. DOI: 10.2169/internalmedicine.0404-17

20 Choi MK, Hong JY, Chang W, Kim M, Kim S, Jung HA, Lee SJ, Park S, Chung MP, Sun JM, Park K, Ahn MJ and Ahn JS: Safety and efficacy of gemcitabine or pemetrexed in combination with a platinum in patients with non-small-cell lung cancer and prior interstitial lung disease. Cancer Chemother Pharmacol 73: 1217-1225, 2014. PMID: 24696125. DOI: $10.1007 / \mathrm{s} 00280-014-2458-0$
Received July 19, 2019

Revised August 2, 2019

Accepted August 7, 2019 